\title{
Divergence time estimation of an ancient relict genus Mankyua (Ophioglossaceae) on the young volcanic Jejudo Island in Korea
}

\author{
Hee-Young GIL and Seung-Chul KIM*
}

\author{
Department of Biological Sciences, Sungkyunkwan University, Suwon 16419, Korea
}

(Received 15 December 2017; Revised 3 March 2018; Accepted 12 March 2018)

\begin{abstract}
Mankyua chejuense is the only member of the monotypic genus Mankyua (Ophioglossaceae) and is endemic to Jejudo Island, Korea. To determine the precise phylogenetic position of $M$. chejuense, two cpDNA regions of 42 accessions representing major members of lycophytes are obtained from GenBank and analyzed using three phylogenetic analyses (maximum parsimony, maximum likelihood, and Bayesian inference). In addition, the divergence time is estimated based on a relaxed molecular clock using four fossil calibration points. The phylogenetic position of Mankyua still appears to be uncertain, representing either the earliest diverged lineage within Ophioglossaceae or a sister to the clade containing Ophioglossum and Helminthostachys. The most recent common ancestor of Ophioglossaceae and its sister lineage, Psilotum, was estimated to be $256 \mathrm{Ma}$, while the earliest divergence of Mankyua was estimated to be $195 \mathrm{Ma}$ in the early Jurassic.
\end{abstract}

Keywords: Mankyua chejuense, monotypic genus, Jejudo Island, molecular dating, Ophioglossaceae

The Korean peninsula, which is on the far east coast of Asia, has rich floristic diversity compared to its relatively small size (Park, 2005). It can be divided into three floristic regions with adjacent regions (i.e., China, Japan, and Far Eastern Russia) and possess diverse habitats due to topographic and climatic complexities (Park, 2005; Chang et al., 2011). Although large number of taxa in the Korean peninsula are shared with adjacent regions, seven genera are endemic to the Korean peninsula, including Mankyua B.-Y. Sun, M. H. Kim \& C. H. Kim (Ophioglossaceae), Megaleranthis Ohwi (Ranunculaceae), Pentactina Nakai (Rosaceae), Echinosophora Nakai (Fabaceae), Abeliophyllum Nakai (Oleaceae), Hanabusaya Nakai (Campanulaceae), and Coreanomecon Nakai (Papaveraceae) (Park, 2005; Kim and Park, 2013). All these genera are monotypic, which comprises single species, except for Hanabusaya [H. asiatica (Nakai) Nakai, H. latisepala Nakai]. Recent molecular phylogenetic studies shed light on the origin of these Korean endemic genera and their status as endemic genera (e.g., Abeliophyllum, Kim et al., 2000; Echinosophora, Lee et al., 2004; Hanabusaya, Roquet et al., 2008; Mankyua, Sun et al., 2009; Megaleranthis, Kim et al., 2009; Pentactina,
Lee and Hong, 2011). Echinosophora, however, is currently treated as Sophora (Lee et al., 2004). Due to continuing decline in quality and quantity of habitat, all endemic genera of Korea were classified as threatened categories of IUCN Red List Categories (Abeliophyllum, endangered [EN]; Pentactina, critically endangered [CR]; Hanabusaya asiatica, EN; Mankyua, CR; Megaleranthis, EN), except for Coreanomecon (Chang et al., 2016). Several phylogenetic and population genetic studies have been conducted for these endemics but their divergence times from their sister lineages have not been determined. This lack of estimated divergence time hinders us to fully understand the origin and evolution of endemic genera in the Korean peninsula as well as to manage and develop conservation strategy of highly threatenened and valuable floristic members in Korea.

Mankyua chejuense B.-Y. Sun, M. H. Kim \& C. H. Kim (Ophioglossaceae) is the only member of the genus Mankyua and is endemic to Jejudo Island, Korea. This monotypic genus has unique combination of morphological characters which differ from other genera of Ophioglossaceae (i.e., trophophore blade, trophophore venation, sporophore, and sporangium).

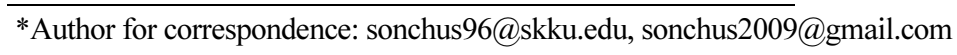


Since it has unique morphology and is rare and endemic to volcanic island, considerable attention has been focused on this enigmatic species. Several studies about morphology, phenology, molecular phylogenetics, conservation, and population genetics were conducted (Chung et al., 2010; Hyeon et al., 2010, 2011; Hyun et al., 2014; Kim et al., 2014; Stuessy et al., 2014). Although previous phylogenetic studies have examined the relationships within Ophioglossaceae (Sun et al., 2009; Shinohara et al., 2013), phylogenetic position of Mankyua is still controversial.

Jejudo island is of volcanic origin and $90 \mathrm{~km}$ south off the coast of the Korean peninsula (Woo et al., 2013). While the family Ophioglossaceae is early diverged basal lineage of monilophytes group, Jejudo Island is very young with the age of approximately 2 million years old (Woo et al., 2013). Since Jejudo Island has recurrently connected to adjacent continents during the glacial cycles in the Quaternary Period, the flora of Jejudo Island has been affected by the various floristic elements from the Korean peninsula, China, and Japan, where habitats are diverse. Despite continuous interests on this highly enigmatic old lineage of Ophioglossaceae, there has been no attempt to estimate the divergence time of Mankyua, specifically for its split from the closest lineage and the crown age. Therefore, in the present study, we explored the phylogenetic position of Mankyua within Ophioglossaceae and estimated the divergence time of $M$. chejuense.

\section{Materials and Methods}

\section{DNA sequence and phylogenetic analyses}

All DNA sequences were retrieved from GenBank (Appendix 1). The $r b c L$ and $m a t K$ sequences were aligned using CLUSTAL W (Larkin et al., 2007), implemented in Geneious version 7.1.7 (Kearse et al., 2012). The alignment was further examined and slightly edited manually as necessary. For the combined cpDNA datasets, we selected six taxa of two genera, Huperzia and Isoetes, as outgroups (Pryer et al., 2004). A total of 42 accessions for 37 taxa were used for phylogenetic analysis. The combined data set was analyzed by maximum parsimony (MP), maximum likelihood (ML), and Bayesian inference (BI) method. The MP phylogenetic analyses was performed using PAUP* version $4.0 \mathrm{~b} 10$ (Swofford, 2002). Characters were treated as unordered and all character transformations were weighted equally. The MP analyses were conducted using heuristic search options with simple stepwise addition of taxa, tree-bisection-reconnection branch swapping, and saving multiple trees. Bootstrap values (Felsenstein, 1985) were calculated from 1,000 replicate analyses using the same heuristic search options as above. Gaps were treated as missing data. For the ML and BI analysis, the best-fit model was selected based on the Akaike information criterion implemented in the program jModelTest version 2.1.6 (Darriba et al., 2012). For both ML and BI analysis, GTR + $\mathrm{I}+\mathrm{G}$ model was selected. ML analyses were conducted using RAxML 8.0.26 (Stamatakis, 2014) implemented in raxmlGUI version 1.3.1 (Silvestro and Michalak, 2012). ML trees were calculated using 1,000 rapid bootstrap inferences. BI analysis was performed with 5,000,000 generations initiated with a random starting tree, sampling every 500 generations and allowing the program to estimate the likelihood parameters required. We discarded $25 \%$ of the samples as burn-in.

\section{Divergence time estimation}

Divergence times of the family Ophioglossaceae and major lineages within the family were estimated by BI approach using the program BEAST v.2.3.1 (Bouckaert et al., 2014). Huperzia and Isoetes were excluded from the analysis to reduce the computational burden. As earlier study of molecular dating of ferns (monilophytes (Pryer, 2014)), we used four fossil calibration points to estimate the divergence time of Ophioglossaceae. We incorporated four fossil constraints from a reassessment of the fern fossil record and the root of the resulting tree was used as a calibration point based on the concurrent appearance of fossils belonging to each of these lineages in the Middle Devonian. We employed a relaxed molecular clock model (Drummond et al., 2006) relying on uncorrelated rates drawn from a log-normal distribution, and a Yule tree prior for speciation. Two independent Markov chain Monte Carlo runs were performed with 5,000,000 generations each, with every 500 generation sampled. A burnin of $10 \%$ per run was discarded after assessing convergence with Tracer version 1.4.1. To obtain an estimate of the phylogenetic tree with mean divergence time and $95 \%$ highest posterior density (HPD) intervals, the program TreeAnnotator v.1.7.5 was used as it summarizes the post burn-in trees and their parameters.

\section{Results}

\section{Phylogenetic position of Mankyua}

The combined cpDNA data set included a total of 42 accessions. A total 2,032 aligned sites for concatenated cpDNA characters were used for MP, ML, and BI analyses. Of the 2,032 characters, 836 were constant, 123 were variable but parsimony-uninformative, and 1,073 were parsimonyinformative characters. The MP analysis found one most 


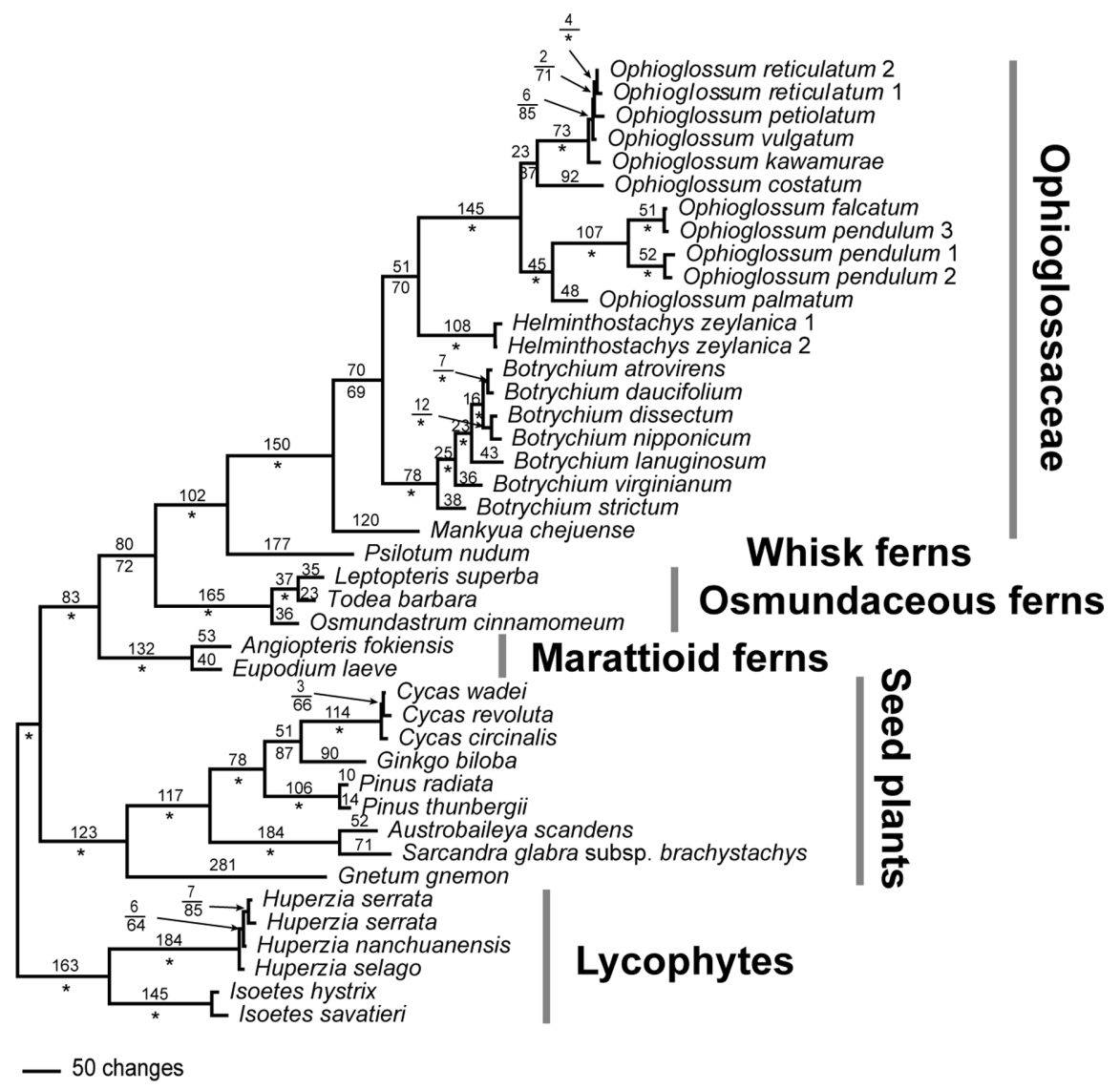

Fig. 1. Maximum parsimony tree based on $r b c L+m a t K$ data. Numbers above braches represent number of mutations, while numbers below braches represent bootstrap support (maximum parsimony bootstrap support). Asterisks show branches with strong ( $\geq 90 \%)$ bootstrap support.

parsimonious tree (Fig. 1) with a tree length of 4,350, a consistency index of 0.4570 (0.4388 excluding uninformative characters), and a retention index of 0.7862 .

Since some topological incongruences were found among ML/BI and MP trees, our results and discussion are based on ML (Fig. 2) and MP (Fig. 1) trees. As shown in both MP and ML trees, the family Ophioglossaceae is monophyletic with strong support value (posterior probability [PP] 1, ML bootstrap support [BS] 100\%, MP BS 100\%). In addition, the monophyly of three genera (Botrychium, Ophioglossum, and Helminthostachys) is strongly supported (PP 1, ML BS 100\%, MP BS 100\%). In ML and BI trees, Botrychium was resolved as the earliest diverged lineage of Ophioglossaceae clade (PP 1, ML BS 100\%) and showed sister relationship with the clade containing remaining three other genera in Ophioglossaceae (Fig. 2). Mankyua shared its most recent common ancestor (MRCA) with Helminthostachys and Ophioglossum (PP 0.92, ML 46\%). However, MP tree demonstrated that Mankyua was resolved as the earliest diverged lineage in Ophioglossaceae (MP BS 69\%) (Fig. 1).

\section{Divergence time estimation}

To estimate the ages for major clades within Ophioglossaceae, we conducted Bayesian analyses using BEAST to obtain $95 \%$ HPDs for the nodes of interest. The maximum-credibility tree based on the relaxed molecular clock analysis of Ophioglossaceae using four fossil calibration points is shown in Fig 3. The stem and crown age of Ophioglossaceae was estimated to be $256 \mathrm{Ma}$ and $195 \mathrm{Ma}$, respectively (during the late Permian and Triassic) (Fig. 3). Mankyua was the earliest lineage diverged during the early Jurassic (195 Ma), with the MRCA of three genera Botrychium, Helminthostachys, and Ophioglossum. Botrychium diverged from the remaining Helminthostachys + Ophioglossum lineages approximately 167 Ma, with Helminthostachys and Ophioglossum splitting from one another during the early Cretaceous (141 Ma) (Fig. 3). Ophioglossum subsequently diverged into two lineages in the Mid Cretaceous (100 Ma) (Fig. 3). The MRCA of Botrychium and Ophioglossum was estimated to be $85 \mathrm{Ma}$ and $100 \mathrm{Ma}$, respectively. 


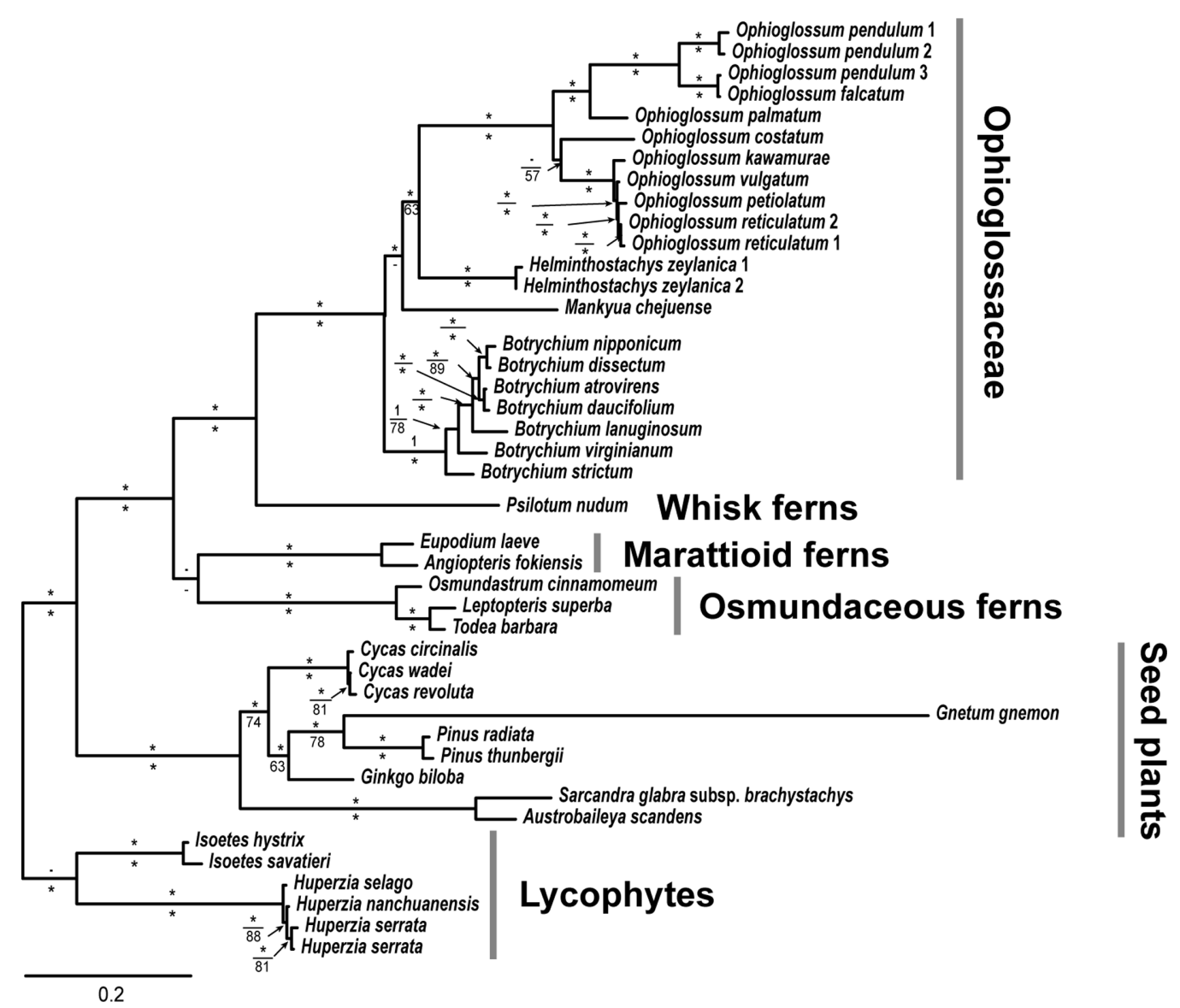

Fig. 2. Maximum likelihood tree based on $r b c L+m a t K$ data. Numbers above and below braches represent Bayesian inference posterior probability and maximum likelihood bootstrap support, respectively. Asterisks show branches with $\geq 0.9$ posterior probabilities and $\geq 90 \%$ bootstrap supports. Hyphen symbols indicate bootstrap supports $\leq 50 \%$.

\section{Discussion}

The phylogenetic position of Mankyua within Ophioglossaceae clade in MP and ML/BI analyses differs significantly. The ML and Bayesian trees (Fig. 2) indicate that Botrychium was resolved as the earliest-diverging lineage of Ophioglossaceae, and that Mankyua is the sister to the clade containing Ophioglossum and Helminthostachys with low ML bootstrap support. In the MP tree (Fig. 1), however, Mankyua was diverged first in Ophioglossaceae clade and Botrychium and Helminthostachys + Ophioglossum showed sister relationship with moderate bootstrap support (MP BS, 69\%). In the previous studies, Sun et al. (2009) presented MP and neighbor joining (NJ) trees of Ophioglossaceae using $r b c L$ data and showed that Ophioglossum diverged first and sister to the clade containing Mankyua, Botrychium and Helminthostachys. Mankyua showed sister relationship with the clade containing Botrychium and Helminthostachys with low bootstrap support. Shinohara et al. (2013) pointed out that MP and NJ approaches are sensitive to long-branch attraction (Sanderson et al., 2000; Anderson and Swofford, 2004), supporting the ML tree topology based on the $r b c L$ and $m a t K$ data set. According to the result of Shinohara et al. (2013), Mankyua is the earliestdiverging lineage in Ophioglossaceae clade and Botrychium was sister to the clade containg Helminthostachys and Ophioglossum with moderate support value. Although the same data sets of Shinohara et al. (2013) and more outgroup taxa were analyzed in our study, phylogenetic position of Mankyua was different from that of Shinohara et al. (2013), providing no concrete position of Mankyua.

In terms of morphological characteristics, Mankyua and Helminthostachys shares major characteristics associated with vegetative organ (i.e., creeping rhizomes, alternate leaf arrangement, and ternately compound trophophore blade) and reproductive organ morphological characteristics of Mankyua are shared with Ophioglossum (i.e., linear and fleshy sporophore, sunken and horizontally dehiscent sporangium), suggesting Mankyua is much resemble with Helminthostachys 


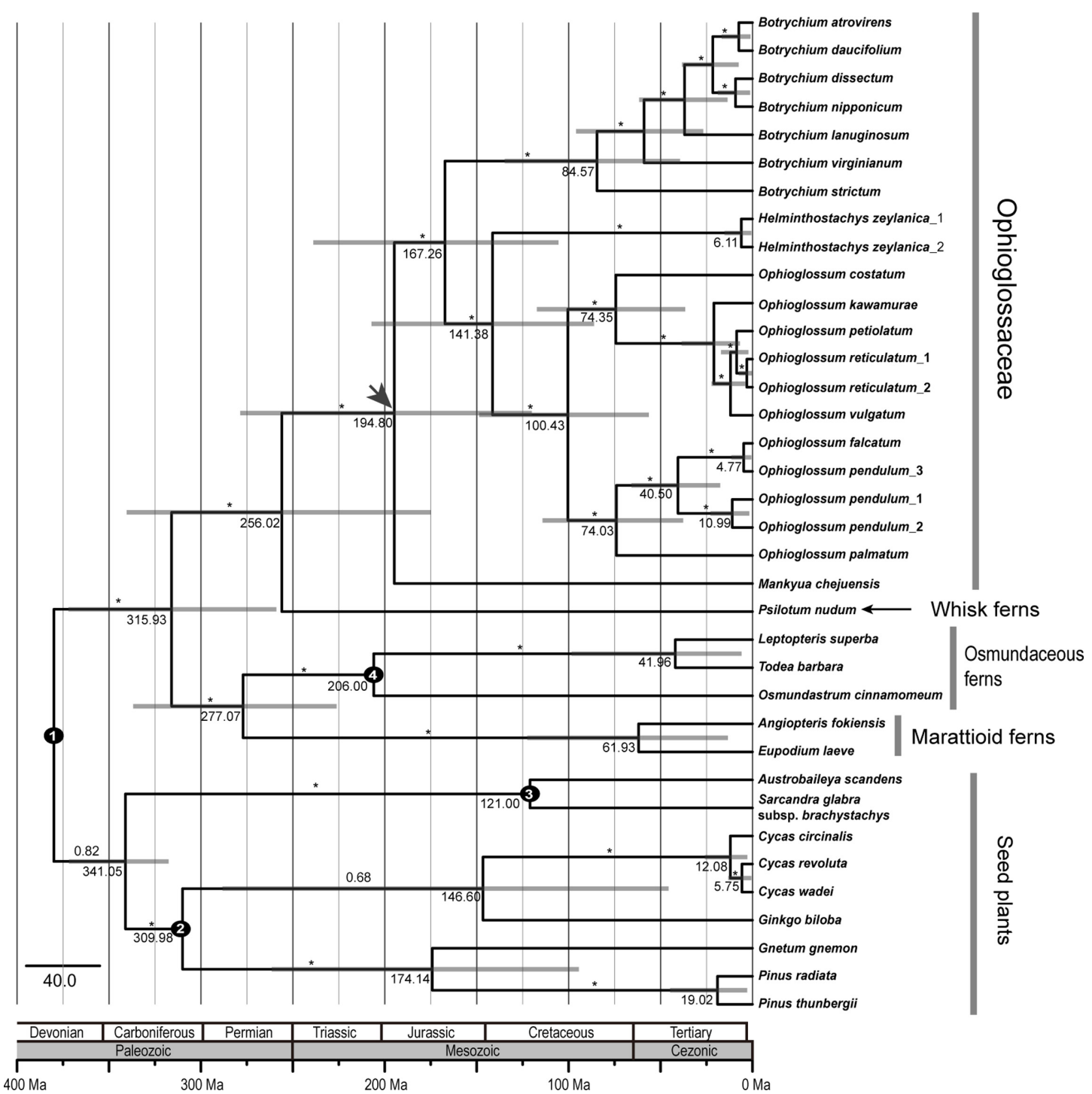

Fig. 3. Maximum clade credibility tree of Ophioglossaceae. Fossil calibration points are indicated by numbers ( 1 through 4$)$ embedded in black circles: node 1 (380 Ma) (Kenrick and Crane, 1997; Pryer et al., 2004); node 2 (310 Ma) (Miller, 1999); node 3 (121 Ma) (Friis et al., 1994, 1999); and node 4 (206 Ma) (Miller, 1971). Divergence time estimates in million years (Ma) are indicated at node and gray bars at the nodes correspond to the $95 \%$ highest posterior density. Asterisks show branches leading to clades with $\geq 90 \%$ posterior probability.

and Ophioglossum rather than Botrychium (Sun et al., 2001). Shinohara et al. (2013) reported the chromosome number of Mankyua $(\mathrm{x}=130)$, the highest base chromosome number in Ophioglossaceae, and compared with other genera in Ophioglossaceae. While outgroups (Angiopteris and Psilotum) have low base chromosome numbers of $\mathrm{x}=40$ and 52, respectively, the most genera of Ophioglossaceae have high base chromosome numbers (Ophioglossum, $\mathrm{x}=120$; Helminthostachys, $\mathrm{x}=94)$ but Botrychium $(\mathrm{x}=44,45$, and 46) (Shinohara et al., 2013). Thus, they suggested that the initial chromosome number of this family was seemed low and increased through polyploidization events, which are common in ferns and lycophytes. Despite several previous studies, we still have room to carry out more detailed morphological, cytological and molecular phylogenetic studies to determine precise phylogenetic position of Mankyua and to resolve phylogenetic relationships among major lineages within Ophioglossaceae.

For the first time, we estimated divergence time of Korean endemic and monotypic genus Mankyua chejuense. Molecular dating tree showed no major topological incongruence with the ML tree except Mankyua chejuense and Ginkgo biloba (Figs. 2, 3). The family Ophioglossaceae diverged during the Permian $(256 \mathrm{Ma})$, the late Paleozoic, with a crown age of 
$195 \mathrm{Ma}$, the late Jurassic in Mesozoic (Fig. 3). In the previous study, Pryer et al. (2004) estimated the divergence time and origin and diversification of major fern clades including Ophioglossaceae. According to the results of their study, the origin of Ophioglossaceae was estimated to be $306 \mathrm{Ma}$, the late Carboniferous, in the Paleozoic, with a crown age of $161 \mathrm{Ma}$ in the Jurassic, the mid Mesozoic era. Since we have incorporated more extensive taxon sampling of Ophioglossaceae, we suggest that our current results may reflect more accurate divergence time of Ophioglossaceae.

Our molecular dating tree (Fig. 3) indicated that Mankyua shared the MRCA with Botrychium, Ophioglossum, and Helminthostachys in approximately $195 \mathrm{Ma}$, the early Jurassic period in the Mesozoic era. Mankyua chejuense is the only surviving member of genus Mankyua, basal lineage of monilophytes. This ancient relic species, M. chejuense, is distributed in highly restricted area $(5.7 \mathrm{~km} \times 4 \mathrm{~km})$, northeastern part of young Jejudo Island, dominated by Ulmus, Cudrania, Camellia, Ligustrum, and Rosa species with small population sizes (Kim, 2004; Chung et al., 2010; Hyeon et al., 2010, 2011). Previous population genetic study of Mankyua with allozyme markers (Chung et al., 2010) revealed extremely lower levels of genetic diversity $\left(\mathrm{H}_{\mathrm{ES}}=0.007, \mathrm{H}_{\mathrm{EP}}=0.005\right)$ than other Korean endemic genera (Abeliophyllum distichum, $\mathrm{H}_{\mathrm{ES}}=0.143, \mathrm{H}_{\mathrm{EP}}=0.110$, Chung, 1999; $\mathrm{H}_{\mathrm{ES}}=0.178, \mathrm{H}_{\mathrm{EP}}=$ 0.13, Kang et al., 2000; Hanabusaya asiatica, $\mathrm{H}_{\mathrm{ES}}=0.217$, Chung et al., 2001; Megaleranthis saniculifolia, $\mathrm{H}_{\mathrm{ES}}=0.088$, Chang et al., 2005; $\mathrm{H}_{\mathrm{ES}}=0.151, \mathrm{H}_{\mathrm{EP}}=0.083, \mathrm{~h}=0.135$ [intersimple sequence repeat, ISSR], Jeong et al., 2010). In addition, Chung et al. (2010) found that high degree of popualtion differentiation in Mankyua chejuense and suggested that founder effect and intragametophytic self-fertilization contributed to such pattern of genetic diversity and differentiation. Very surprisingly, we found similar genetic patterns in another monotypic genus, Lactoris (Lactoridaceae), which is also considered the remnant of an old angiosperm lineage and endemic to the Juan Fernández Archipelago (ca. 4 million years old). Comprehensive population genetic studies are conducted with various molecular markers (i.e., ribosomal DNA length, randomly amplified polymorphic DNA, allozyme, and ISSR), but lack of or low genetic diversity was found within populations (Brauner et al., 1992; Crawford et al., 1994, 2001). Furthermore, Crawford et al. (2001) found over $73 \%$ of the ISSR diversity occurred across populations, suggesting very high degree of population differentiation. For the major factors responsible for this genetic patterns, founder effect, genetic drift associated with small population sizes, and a selfing breeding system have been suggested. To better understand for Mankyua chejuense, comprehensive studies of morphology, ecology, breeding system, and population genetics with other highly variable and informative molecular markers would be rewarding. In addition, it would be of great value to estimate the origin and divergence time of other Korean endemic genera to have better picture on these valuable floristic elements in the Korean peninsula.

\section{Conflict of Interest}

Authors declare that there is no conflict of interest.

\section{Acknowledgments}

This study was supported in part by the Korean Research Foundation (NRF-2016R1D1A2B03934). We woud like to thank the comments and suggestions from the two annonymous reviewers.

\section{Literature Cited}

Anderson, F. E. and D. L. Swofford. 2004. Should we be worried about long-branch attraction in real data sets? Investigations using metazoan 18S rDNA. Molecular Phylogenetics and Evolution 33: 440-451.

Bouckaert, R., J. Heled, D. Kühnert, T. Vaughan, C.-H. Wu, D. Xie, M. A. Suchard, A. Rambaut and A. J. Drummond. 2014. BEAST 2: a software platform for Bayesian evolutionary analysis. PLoS Computational Biology 10: e1003537.

Brauner, S., D. J. Crawford and T. F. Stuessy. 1992. Ribosomal DNA and RAPD variation in the rare plant family Lactoridaceae. American Journal of Botany 79: 1436-1439.

Chang, C.-S., D. Y. Choi, H. Kim, T. Y. Park and Y.-S. Kim. 2005. Patterns of allozyme variation in relation to population size of the threatened plant Megaleranthis saniculifolia (Ranunculaceae) in Korea. Journal of Plant Biology 48: 339-350.

Chang, C.-S., H. Kim and G. S. Chang. 2011. Illustrated Encyclopedia of Fauna \& Flora of Korea Vol. 43. Woody Plants. Ministry of Education, Seoul, 511 pp.

Chang, C.-S., H. Kim, S. Son and Y.-S. Kim. 2016. The Red List of Selected Vascular Plants in Korea. Korea National Arboretum and Korean Plant Specialist Group, Pocheon, 50 pp.

Chung, M. G. 1999. Allozyme diversity in the endangered shrub Abeliophyllum distichum (Oleaceae): a monotypic Korean genus. International Journal of Plant Sciences 160: 553-559.

Chung, M. G., M. Y. Chung and B. K. Epperson. 2001. Conservation genetics of an endangered herb, Hanabusaya asiatica (Campanulaceae). Plant Biology 3: 42-49. 
Chung, M. Y., J. D. Nason, B.-Y. Sun, M.-O. Moon, J. M. Chung, C.-W. Park and M. G. Chung. 2010. Extremely low levels of genetic variation in the critically endangered monotypic fern genus Mankyua chejuense (Ophioglossaceae) from Korea: implications for conservation. Biochemical Systematics and Ecology 38: 888-896.

Crawford, D. J., T. F. Stuessy, M. B. Cosner, D. W. Haines, D. Wiens and P. Penaillo. 1994. Lactoris fernandeziana (Lactoridaceae) on the Juan Fernandez Islands: allozyme uniformity and field observations. Conservation Biology 8: 277-280.

Crawford, D. J., M. Tago-Nakazawa, T. F. Stuessy, G. J. Anderson, G. Bernardello, E. Ruiz, R. J. Jensen, C. Baeza, A. D. Wolfe and M. Silva O. 2001. Intersimple sequence repeat (ISSR) variation in Lactoris fernandeziana (Lactoridaceae), a rare endemic of the Juan Fernandez Archipelago, Chile. Plant Species Biology 16: 185-192.

Darriba, D., G. L. Taboada, R. Doallo and D. Posada. 2012. jModelTest 2: more models, new heuristics and parallel computing. Nature Methods 9: 772.

Drummond, A. J., S. Y. W. Ho, M. J. Phillips and A. Rambaut. 2006. Relaxed phylogenetics and dating with confidence. PLoS Biology 4: e88.

Felsenstein, J. 1985. Confidence limits on phylogenies: an approach using the bootstrap. Evolution 39: 783-791.

Friis, E. M., K. R. Pedersen and P. R. Crane. 1994. Angiosperm floral structures from the early Cretaceous of Portugal. Plant Systematics and Evolution 8(Supplement): 31-49.

Friis, E. M., K. R. Pedersen and P. R. Crane. 1999. Early angiosperm diversification: the diversity of pollen associated with angiosperm reproductive structures in early Cretaceous floras from Portugal. Annals of the Missouri Botanical Garden 86: 259-296.

Hyeon, H.-J., C.-H. Kang, K.-M. Song, M.-O. Moon, G.-P. Song and M.-H. Kim. 2010. Flora and the conditions of Mankyua chejuense habitats. Korean Journal of Plant Resources 23: 350-359. (in Korean)

Hyeon, H.-J., M.-O. Moon and M.-H. Kim. 2011. Vegetation characteristics of Mankyua chejuense habitats. Korean Journal of Plant Resources 24: 395-403.

Hyun, H.-J., M.-O. Moon, H.-S. Choi and C.-S. Kim. 2014. Growth pattern and phenology of Mankyua chejuense B.-Y. Sun, M.H. Kim \& C.H. Kim. Korean Journal of Plant Resources 27: 95-101. (in Korean)

Jeong, J. H., E. H. Kim, W. Guo, K. O. Yoo, D. G. Jo and Z. S. Kim. 2010. Genetic diversity and structure of the endangered species Megaleranthis saniculifolia in Korea as revealed by allozyme and ISSR markers. Plant Systematics and Evolution 289: $67-76$.
Kang, U., C.-S. Chang and Y. S. Kim. 2000. Genetic structure and conservation considerations of rare endemic Abeliophyllum distichum Nakai (Oleaceae) in Korea. Journal of Plant Research 113: 127-138.

Kearse, M., R. Moir, A. Wilson, S. Stones-Havas, M. Cheung, S. Sturrock, S. Buxton, A. Cooper, S. Markowitz, C. Duran, T. Thierer, B. Ashton, P. Meintjes and A. Drummond. 2012. Geneious basic: an integrated and extendable desktop software platform for the organization and analysis of sequence data. Bioinformatics 28: 1647-1649.

Kenrick, P. and P. R. Crane. 1997. The Origin and Early Diversification of Land Plants: A Cladistic Study. Smithsonian Press, Washington, D.C., 441 pp.

Kim, C. H. 2004. Conservation status of the endemic fern Mankyua chejuense (Ophioglossaceae) on Cheju Island, Republic of Korea. Oryx 38: 217-219.

Kim, C. H. and J. H. Park. 2013. Endemic Species of Korea: Plantae. National Institute of Biological Resources, Incheon, 912 pp.

Kim, H.-R., J.-H. Shin, H.-M. Jeon and Y.-H. You. 2014. Effects of environmental factors on the growth response of above- and below-ground parts of Mankyua chejuense, endangered endemic plant to Jeju province, in Korea. Journal of Ecology and Environment 37: 61-67.

Kim, K.-J., H.-L. Lee and Y.-D. Kim. 2000. Phylogenetic position of Abeliophyllum (Oleaceae) based on nuclear ITS sequence data. Korean Journal of Plant Taxonomy 30: 235-250.

Kim, Y. K., C. W. Park and K. J. Kim. 2009. Complete chloroplast DNA sequence from a Korean endemic genus, Megaleranthis saniculifolia, and its evolutionary implications. Molecules and Cells 27: 365-381.

Larkin, M. A., G. Blackshields, N. P. Brown, R. Chenna, P. A. McGettigan, H. McWilliam, F. Valentin, I. M. Wallace, A. Wilm, R. Lopez, J. D. Thompson, T. J. Gibson and D. G. Higgins. 2007. Clustal W and Clustal X version 2.0. Bioinformatics 23: 2947-2948.

Lee, C. and S.-P. Hong. 2011. Phylogenetic relationships of the rare Korean monotypic endemic genus Pentactina Nakai in the tribe Spiraeeae (Rosaceae) based on molecular data. Plant Systematics and Evolution 294: 159-166.

Lee, W. K., T. Tokuoka and K. Heo. 2004. Molecular evidence for the inclusion of the Korean endemic genus "Echinosophora" in Sophora (Fabaceae), and embryological features of the genus. Journal of Plant Research 117: 209-219.

Miller, C. N. 1971. Evolution of the fern family Osmundaceae based on anatomical studies. Contributions from the Museum of Paleontology The University of Michigan 23: 105-169.

Miller, C. N. 1999. Implications of fossil conifers for the phylo- 
genetic relationships of living families. The Botanical Review 65: 239-277.

Park, C.-W. 2005. Recent progress in floristic research in Korea. Progress in Botany 67: 345-360.

Pryer, K. M., E. Schuettpelz, P. G. Wolf, H. Schneider, A. R. Smith and R. Cranfill. 2004. Phylogeny and evolution of ferns (Monilophytes) with a focus on the early leptosporangiate divergences. Amercan Journal of Botany 91: 1582-1598.

Roquet, C., L. Sáez, J. José Aldasoro, A. Susanna, M. L. Alarcón and N. Garcia-Jacas. 2008. Natural delineation, molecular phylogeny and floral evolution in Campanula. Systematic Botany 33: 203-217.

Sanderson, M. J., M. F. Wojciechowski, J. M. Hu, T. S. Khan and S. G. Brady. 2000. Error, bias, and long-branch attraction in data for two chloroplast photosystem genes in seed plants. Molecular Biology and Evolution 17: 782-797.

Shinohara, W., N. Nakato, Y. Yatabe-Kakugawa, T. Oka, J. K. Kim, N. Murakami, H. Noda and N. Sahashi. 2013. The use of $m a t K$ in Ophioglossaceae phylogeny and the determination of Mankyua chromosome number shed light on chromosome number evolution in Ophioglossaceae. Systematic Botany 38: 564-570.

Silvestro, D. and I. Michalak. 2012. RaxmlGUI: a graphical front- end for RAxML. Organisms Diversity \& Evolution 12: 335337.

Stamatakis, A. 2014. RAxML version 8: a tool for phylogenetic analysis and post-analysis of large phylogenies. Bioinformatics 30: 1312-1313.

Stuessy, T. F., K. Takayama, P. López-Sepúlveda and D. J. Crawford. 2014. Interpretation of patterns of genetic variation in endemic plant species of oceanic islands. Botanical Journal of the Linnean Society 174: 276-288.

Sun, B.-Y., T. G. Baek, Y.-D. Kim and C. S. Kim. 2009. Phylogeny of the family Ophioglossaceae with special emphasis on genus Mankyua. Korean Journal of Plant Taxonomy 39: 135142.

Sun, B.-Y., M. H. Kim, C. H. Kim and C.-W. Park. 2001. Mankyua (Ophioglossaceae): a new fern genus from Cheju Island, Korea. Taxon 50: 1019-1024.

Swofford, D. L. 2002. PAUP*: phylogenetic analysis using parsimony (*and other methods), version 4.0b10. Sinauer Associates, Sunderland, MA.

Woo, K., Y. Sohn, U. Ahn, S. Yoon and A. Spate. 2013. Geology of Jeju Island. In Jeju Island Geopark: A Volcanic Wonder of Korea. Vol. 1. Geoparks of the World (closed) (Development and Management). Spriner, Berlin, Heidelberg. Pp. 13-14.

Appendix 1. A list of Genbank accessions included in the present phylogenetic study. Taxon: Genbank accessions: $r b c L$ and $m a t K$.

Mankyua chejuense B. Y. Sun, M. H. Kim \& C. H. Kim: AB626635, AB716726. Helminthostachys zeylanica (L.) Hook.: AB626636, AB716727; AB626637, AB716728. Ophioglossum pendulum L.: AB626638, AB716729; AB626639, AB716730; AB626640, AB716731. Ophioglossum falcatum Fowler: AB626641, AB716732. Ophioglossum palmatum L.: AB626642, AB716733. Ophioglossum costatum R. Br: AB626643, AB716734. Ophioglossum vulgatum L.: AB626644, AB716735. Ophioglossum reticulatum L.: AB626645, AB716736; AB626646, AB716737. Ophioglossum petiolatum Hook.: AB626647, AB716738. Ophioglossum kawamurae Tagawa: AB626648, AB716739. Botrychium strictum Underw.: AB626649, AB716740. Botrychium virginianum (L.) Sw.: AB626650, AB716741. Botrychium daucifolium Wall. ex Hook. \& Grev.: AB626651, AB716742. Botrychium atrovirens M. Kato: AB626652, AB716743. Botrychium lanuginosum Wall. ex Hook. \& Grev.: AB626653, AB716744. Botrychium nipponicum Makino: AB626654, AB716745. Botrychium dissectum Spreng.: AB626655, AB716746. Psilotum nudum (L.) P. Beauv.: AB626657, AB716747. Leptopteris superba C. Presl: DQ646004, KM925081. Todea barbara T. Moore: AB024959, KM925082. Osmundastrum cinnamomeum (L.) C. Presl: AB024949, KJ772969. Angiopteris fokiensis Hieron: AB574693, EF053139. Eupodium leave (Sm.) Murdock: EU439080, KM925080. Austrobaileya scandens C. T. White: L12632, DQ182344. Sarcandra glabra subsp. brachystachys (Blume) Verdc.: KC840122, AF543733. Cycas circinalis L.: L12674, AF410164. Cycas revolute Thunb.: JQ512537, JQ512413. Cycas wadei Merr.: AF394341, AF410163. Ginkgo biloba L.: D10733, AF456370. Gnetum gnemon L.: U72819, AY449621. Pinus radiate D. Don: X58134, AB080934. Pinus thunbergii Parl.: JQ512595, JQ512471. Isoetes hystrix Bory \& Durieu: AF404497, KF997363. Isoetes savatieri Franch.: AF404505, HF585133. Huperzia selago (L.) Bernh. ex Schrank \& Mart.: DQ464227, DQ465962. Huperzia serrata (Thunb.) Trevis.: DQ464228, DQ465963; DQ464224, DQ465959. Huperzia nanchuanensis (Ching \& H. S. Kung) Ching \& H. S. Kung: DQ464226, DQ465961. 